\title{
Finding Our Voice: Highly Flexible ED for the HyFlex World
}

Kristine Larsen, Christina Robinson, Jason Melnyk, Jennifer Nicoletti, Amy Gagnon, Kelly McLaughlin, and Mina Hussaini

\section{Abstract}

The COVID-19 pandemic brought about unprecedented changes in our approach to delivering educational development (ED) programming. In this article we discuss how our dual ED centers pivoted during the sudden switch to online learning, highlighting how we overcame challenges such as a small staff, tight timelines, and faculty anxieties. Particularly, we explore how we adapted to the university's investment in technologically advanced Hybrid-Flexible (HyFlex) classroom spaces and utilized a multi-pronged team approach to provide effective and timely ED to faculty. By identifying key faculty leaders, identifying multiple sources of data, and using multiple modalities, we supported the faculty in their mission to effectively serve their students during this difficult and stressful time. In pivoting from a triage approach to more tactically focused development, the two ED centers discovered that they could more effectively serve faculty (and by extension students) by shattering the structural silos that had previously defined them and instead working as a unified entity.

Keywords: HyFlex, pivot pedagogy, online teaching and learning, teaching with technology 
Educational development (ED) for faculty and staff, traditionally the cornerstone for innovation and a safe place for those who want to push the envelope of pedagogical advancement, took an unprecedented turn in the early days of the COVID-19 pandemic. For many institutions, this was an overdue impetus for change that will deeply impact the landscape of higher education for years to come (Kelly \& Columbus, 2020). On our campus the rush to distance learning in March 2020 exposed deficiencies in faculty knowledge and comfort with technology and online pedagogy as well as highlighted inadequacies in the existing structures of course design and ED to serve faculty remotely and in far larger numbers than previous semesters. While the administration of Central Connecticut State University (CCSU) met the challenges of providing highquality education to a mainly distanced student body through the innovation of high-tech Hybrid-Flexible (HyFlex) classrooms, the shift generated significant ED challenges in preparing and supporting faculty that were best met by creativity and teamwork, ultimately leading to the unification of two previously distinct ED structures on campus.

We present this chronologically structured (and deeply transparent) review of how CCSU responded to the ED challenges created by the COVID-19 pandemic in order to offer recommendations for changes to ED delivery that will remain relevant in the post-pandemic world. After a review of the structures that were in place prior to the COVID-19 pandemic, we examine the immediate ED response in the wake of the initial shutdown of campus. The extensive role played by ED staff in piloting HyFlex education in the fall 2020 semester is described, followed by an examination of the successes and frustrations of the actual implementation of the technology. We conclude by reflecting on the important lessons learned from our experience and how ED at CCSU has been forever changed by the pandemic. 


\section{ED in the "Before Time"}

On the campus of CCSU, a regional comprehensive institution of higher education situated two hours from Boston and New York City and part of the larger Connecticut State Colleges and Universities (CSCU) system, educational development had often been perceived as an afterthought before the pandemic. The primary audience for ED was the self-selected few who were eager to push the envelope. The majority of faculty had been teaching using chalk-and-talk techniques for the last several decades, and even our pioneers were innovating in a traditional classroom-very few were truly embracing the infusion of technology into teaching and learning. With a transition in leadership and vision, and increased support from the university president, faculty and staff were engaging more holistically in ED in the months preceding the pandemic. Our monthly Lunch and Learn series that introduced a pedagogical tool along with discussion and notes from the trenches was already attracting a broader audience from across campus.

Fora medium-sized university with approximately 400 full-timefaculty and as many adjuncts, we had a small-sized interest in technologyinfused pedagogy. Online and remote teaching had a long history of being viewed as a less attractive and less rigorous modality. As a result, in a typical semester, the number of undergraduate courses taught online was limited to 40 by a Faculty Senate resolution, and no more than $50 \%$ of an academic program could be offered online without obtaining special permission. The Faculty Senate cap had never been reached, as faculty opted to teach strictly on ground during the regular semester. These restrictions did not apply to optional summer sessions or the three-week winter "intersession," where student and faculty desires for increased flexibility resulted in the majority of undergraduate courses being offered in an online asynchronous environment. An insignificant number 
of "hybrid" courses, composed of traditional on-ground segments paired with online asynchronous work, had also been offered. Thus, during the pandemic, faculty pivoted to completely online education (both synchronous and asynchronous) in a culture with a negative opinion of such modalities.

Exacerbating this transition was the fact that while the university had adopted Blackboard Learn (BBL) as its official learning management system (LMS) for several years, it was not universally embraced. Some did not use it, others used it merely as a parking lot for their syllabi and course readings, and a few preferred Moodle (an LMS not supported by the university). Therefore, the technological foundation for teaching a completely online course was inconsistent across campus. Even those individuals experienced in online teaching and pedagogy had a limited number of well-loved tools in their toolbox. This lack of standardization was soon to be an important source of angst during the rapid pivot to online that resulted when CCSU abruptly, and without warning, closed its physical campus on March 12, 2020, two days before spring break.

Over the next 10 days, nearly $100 \%$ of faculty were asked to sacrifice their spring break and pivot to fully remote delivery. Support for this mass migration to online course delivery fell to two small EDrelated centers. The Instructional Design and Technological Resource Center (IDTRC) trained faculty and solved problems related to $B B L$ and facilitated online course development. Their website hosts a rich repository of training materials in both written and video format. The staff (previously two, now three full-time and three parttime members) fall under the purview of the Associate Vice President for Graduate Studies, Research, and Faculty Development (AVP). The Center for Teaching and Faculty Development (CTFD) is a faculty-run structure supported by the AVP, composed of a director who receives one course release per semester, a part-time coordinator, and a volunteer board of advisors. Its primary goal is to create opportunities for faculty to share ideas about teaching techniques and pedagogy 
and hone their educational voice. They sponsor workshops, seminars, an ED-related book club, and a competitive Learning Community Group program that provides small grants to facilitate exploration of topics such as universal design for learning (UDL) and age-inclusive teaching and learning.

\section{Triage: Pivot to Online in Spring 2020}

The rapid pivot to online delivery in March 2020 shone a brighter light on several fundamental problems with both ED and the campus culture, as reflected in the section that follows. Before the COVID19 pandemic, nearly all online courses on campus were taught asynchronously; however, as previously noted, the vast majority of faculty had limited experience crafting online courses of any variety. As noted by Miller et al. (2021, p. 1), when forced to transition to an online modality, many faculty desired to "replicate face-to-face pedagogy in virtual online classrooms" through web conferencing software. With very little time to make this substantial change, many found themselves frustrated by the options available to them. CCSU faculty needed to not only choose their platform (the university-supported WebEx or an unsupported platform like Zoom) but learn how to use platformspecific tools and settings. Some faculty elected to record asynchronous lectures but, once again, found themselves drowning in a sea of possibilities and platforms that were largely unfamiliar to them.

Compounding the campus-wide level of stress was the fact that these decisions were made by faculty without knowing which of these myriad choices would serve their students' needs most effectively. Many faculty shared (via phone calls and emails to the IDTRC and posts to the campus-wide Faculty Senate email listserv) that they simply felt overwhelmed and didn't know how to begin moving their courses online. As detailed below, the ED staff met these challenges, but not without significant stresses of their own. 


\section{Addressing Immediate Concerns}

The first step was to adopt a triage approach to ED, in which we assessed each situation and attended to the immediate needs of faculty and students. The IDTRC quickly adapted its programming over spring break, moving from its usual on-ground delivery to an online format that focused on a streamlined list of topics: WebEx (then the default web conferencing platform on campus), BBL, Respondus lockdown browser (i.e., anti-cheating software), and Kaltura lecture capture software for recording lectures. Simultaneously, the AVP, the CTFD director and coordinator, along with the IDTRC supervisor developed a "Survival Guide" that included sample communications that faculty could use to introduce students to their classroom's "new normal," BBL best practices and tools, and UDL resources. A second issue of the guide was delivered to faculty after the first week of online instruction, including tips and resources for dealing with both faculty and student stress and, in response to faculty concerns, strategies to reduce cheating.

\section{Conversations with Colleagues}

The CTFD also shifted its ED programming in response to faculty needs, especially the desire to retain a sense of community while we were separated from campus. Drawing upon prior success with a small program of year-long learning communities (Smith et al., 2004) centered on specific pedagogies, we introduced a new "Conversations with Colleagues" ( $\mathrm{CwC}$ ) series in mid-April. CwC offered hour-long "open-mic" sessions on WebEx where faculty could meet virtually in an informal setting and discuss in a safe, supportive environment any topic of importance to them. Faculty were encouraged to share teaching tips, ask questions, and attempt to maintain a sense of community while we were physically apart, an important step in promoting faculty resilience (Duffield \& O'Hare, 2020). This creation of a "virtual staffroom" (Duffield \& O'Hare, 2020, p. 3) was especially important in 
maintaining an interdisciplinary sense of community across campus, as many campus-wide committees were slow to reconvene online. In order to encourage meaningful conversation, participation was limited to approximately 25 faculty members on a first-come basis.

As the pandemic continued, some of these sessions began to feature advertised topics (meant to scaffold, not restrict conversation), such as developing a sense of community in the virtual classroom (largely in response to feedback from both students and faculty). A core group of attendees quickly emerged, aiding in the creation of a much-needed sense of community. The success of this program mirrors research demonstrating that many faculty find the comfortable exchange of information within informal peer-to-peer interactions to be particularly useful in improving their teaching (Jennings \& Wargnier, 2011).

\section{Training Webinars}

Over the course of the spring semester, faculty ED leaders organically emerged, especially in CwC events. These individuals were eagerly drafted by the AVP and CTFD director to provide ED webinars for their colleagues. At the same time, the efforts of the IDTRC to offer web-based training for faculty were hitting a snag. Due to the large number of faculty requesting individualized help and training, there was not enough staff to handle the increased volume of requests.

Fortunately, collegial teamwork between the office of the AVP, CTFD, and IDTRC was facilitated by the AVP, a seasoned faculty member at the institution who had been interim in the role for nine months at the time of the pivot. Drawing upon the natural synergies and sense of teamwork that had already begun to develop between the AVP, IDTRC, and CTFD, one of the CTFD's board members was designated as a Special Assistant to the AVP (SA). Working together, the CTFD director, the SA, and another self-identified faculty ED leader were given access to the IDTRC's group email address, creating a new, united ED team. The faculty could answer ED questions and 
offer individualized tips to fellow faculty (to the limits of their personal expertise), freeing up the IDTRC staff to deal with the more complex software issues. This teamwork proved especially useful in large training webinars where attendance often surpassed 100.

Faculty came to the web conference-based ED with prepared questions and single-pointed interests, which required a tactful pivot in our delivery techniques. For instance, presenters were immediately bombarded with myriad questions about steps further downstream. To regain order, attendees were muted upon entry, and we responded only to questions posed in the written chat. Two ED team members monitored the chat and answered simple questions as they came up, leaving the more complex questions for the presenters to answer at logical pause points. This preserved the flow of the session and allowed all content to be covered.

\section{Needs Assessment}

An "Applause and Alerts" survey sent to students in early April confirmed that many of the faculty were utilizing the ED offered to them and successfully making the pivot to online delivery despite the adverse conditions. However, the survey indicated that some students were frustrated with the smaller, more frequent assignments many faculty were offering, viewing them as "busy work." Students expressed similar concerns in focus groups sponsored by the provost's office. As reported in the student newspaper, some students considered the asynchronous coursework many faculty were offering to provide flexibility to their students as material faculty "haven't actually taught" (Chan, 2020). In all venues students frequently voiced missing the personal connection that is easier to establish in person than through the computer. To help faculty address these challenges and meet the students where they were, the ED team carefully planned our Connecting with Colleagues and Lunch and Learn topics to provide faculty with additional pedagogical choices they could institute going forward. We had survived one semester and turned our sight toward an uncertain future. 


\section{Brave New World: Preparing for HyFlex}

In a typical year, ED at CCSU tended to shift over the summer, with IDTRC workshops becoming both more focused in content (e.g., "boot camps" in the use of BBL) and less frequent in their scheduling. CTFD normally refrained from offering any programming over the summer, ending the spring semester with a campus-wide celebration of teaching and learning (including the Excellence in Teaching awards) and kicking off the fall semester with an equally large half-day ED workshop on a timely topic (such as the August 2019 workshop on the needs of "Gen Z" students). However, in reflecting upon their experiences of the spring semester, and faced with the uncertainty of the fall semester to come, faculty and administration alike understood that this was to be a summer like no other.

As described by Kelly and Columbus (2020, p. 4), the COVID-19 pandemic pivot to online teaching was largely a "jury-rigged model" that "bore little resemblance to state-of-the-art delivery." This was especially true at institutions such as ours with limited experience in online education. Therefore, the design and implementation of highquality online courses that reflect best practices in pedagogy and take full advantage of available technological tools would be a timeintensive endeavor (Major, 2020). In response, the CTFD continued offering ED over the summer, including both the smaller peer support system-oriented $\mathrm{CWC}$ and larger, more highly structured ED webinars. Similarly, IDTRC revisited its usual suite of summer offerings, expanding and revising them to reflect the needs of faculty. In the case of both arms of the ED house, the watchword became "flexibility" in response to a number of unexpected challenges and opportunities explained in this section, including the introduction of a massive HyFlex program.

In late May, while some faculty prepared for summer courses and summer ED opportunities, it was announced that the university was investing significant resources to convert roughly three dozen classrooms (roughly one-third of the computer-equipped traditional 
classrooms) into socially distanced, HyFlex-spaces (Beatty, 2019). To meet the needs of our students and offer sufficient opportunities to return to campus, the stated goal was to offer at least $40 \%$ of course sections in this mixed on-ground/online modality. These HyFlex classrooms were subsequently equipped with broadcast-quality cameras and microphone arrays, including software that would simultaneously record and broadcast lectures that would be automatically uploaded directly to the BBL course shell. In addition, about a dozen studio and lab spaces were equipped with portable HyFlex carts. Identifying courses for HyFlex delivery was an iterative process that necessitated careful balancing of programmatic considerations, student demand, and faculty desire to teach on campus. Courses that required hands-on learning and could be done following all safety guidelines (i.e., nursing and some lab-based sciences) were prioritized, as were courses traditionally taken by first-year and sophomore students.

As described by Beatty (2019), the HyFlex course model is one in which students can choose to attend a class online (either synchronously or asynchronously), on ground, or a mixture of the two, depending on changing student need. Faculty are responsible for developing assessments and delivering course content in ways that are equitably accessible to students attending in any of these modalities, necessitating an increased faculty workload in terms of course development, communication, and management (Beatty, 2019). Skibba (2007) notes that four roles are simultaneously played by faculty in a hybrid class, with the relative weight constantly shifting in response to the needs of the students and the rhythm of the semester: pedagogical (design and delivery of the course material); social (construction of the course community, including facilitating communication); managerial (coordination of assessments and course scheduling); and technological (facilitating student use of the LMS).

Faculty were understandably anxious about adopting a pedagogy they had largely never heard of, especially given the amount of time and effort they had put into moving their courses online on such short notice. With an eye toward keeping faculty and students as safe as 
possible in the face of uncertain conditions, students could not cycle through the on-ground seats and were required to register for a completely online synchronous experience (watching live broadcasts) or for an on-ground seat, which would afford them the opportunity to either attend in person or online, as personal and campus situations allowed. It was also decided that HyFlex classes would go fully remote for the last week of the semester (after Thanksgiving break). With these parameters set, faculty awaited the availability of relevant ED training materials and workshops; however, the ED team could not provide these resources until they themselves were sufficiently familiar with the technology.

Despite the best efforts of all involved, unavoidable delays occurred in both the hardware and software installation. A prototype room was made available to the ED team in late June, and their feedback was used to make minor adjustments in the system and classroom setup. A 30-second delay in the live broadcast was quickly identified as a major problem but appeared unavoidable with the available software. Fortunately, Blackboard Collaborate (BBC), with its built-in chat function, was made available to CSCU campuses in late July and was adopted by the ED team as the recommended methodology of communicating with online synchronous students in the HyFlex environment. Joining the late-summer rollout of BBC was GoReact, a tool that facilitates video-based interaction between faculty and students. Individual and cohort-based Quality Matters course design training was also provided. This embarrassment of riches proved stressful for both faculty and the ED team, with the latter scrambling to provide adequate training and support and the former voicing dissatisfaction with the late timing of implementation.

Delays in the HyFlex classroom completion continued to complicate the creation of training materials and experiences, with minor system changes being made until the very start of the semester. Some outdated information was therefore inadvertently shared in both the documentation and the first iteration of training sessions, a source of understandable frustration. The ED team quickly learned that faculty, 
like students, wanted material presented in manageable chunks. For example, a highly detailed BBC manual was labeled "intimidating" by individual faculty members during an online training session. Thus, no single user guide for HyFlex classroom utilization was constructed. Instead, the IDTRC and CTFD training materials were posted as a series of bite-sized morsels, explaining discrete parts of the process in a logical order. Both short videos (under 10 minutes) and brief (under five pages) step-by-step guides (with numerous screen captures) were preferred by faculty, with the former frequently cited as particularly helpful.

Faculty teaching HyFlex had to adapt not only to the new hardware/software and teaching to a hybrid audience but also to shorter time blocks (50 minutes vs. 75 minutes), needed to facilitate cleaning of the classrooms. Two webinars introduced faculty to an online resource dubbed the THING (Taking Hybrid/HyFlex Interaction to the Next Generation) that provided specific examples of how to shift synchronous activities to comparable asynchronous ones (https://drive. google.com/file/d/1JZIJ6lOcg1MHXFAgSNHA-uRrdmJV82yQ/view).

While faculty ED participation was more than we could handle in the beginning, by the time the HyFlex classrooms became available for $E D$, we were already seeing symptoms of compassion fatigue in our faculty, as summarized by Cordaro (2020). Our previously eager faculty were physically and emotionally exhausted, feeling overwhelmed and unable to do more. They were also reporting a lack of purpose and motivation, questioning the validity of the work they were doing more and more frequently and feeling disappointed with the outcomes of their efforts, signaling that our faculty were simultaneously battling burnout as well (Hogan \& McKnight, 2007). For example, faculty began to voice significant pushback during webinar trainings, including accidental "hot mic" moments. While they were vigorously encouraged to contribute additional examples of asynchronous assignments to the THING described above (as it was intended to be a "living document"), faculty were instead passive consumers of the training offered to them.

A more concerning warning sign was the low attendance at the kick-off HyFlex webinars on August 17 and 19, for which only half of 
the expected participants attended. Likewise, the 39 one-hour, onground trainings offered in a HyFlex classroom from August 12 to August 21 (limited to five participants each) were only half-subscribed. Faculty demonstrably preferred the handful of "practice" rooms made available to allow instructors the freedom to test drive at their own pace. There was still significant anxiety among the faculty who wanted to practice in "their" classroom, a well-founded concern, as individual rooms had unique "quirks" (e.g., additional smart-boards, inconsistently labeled displays, cameras in large rooms that featured fewer options than those in standard-sized classrooms). As with any new technology, problems arose as written directions couldn't fully account for all possibilities, requiring flexibility on the part of both the faculty and the ED team. In these cases, low-tech ancillary videos (some filmed with a cell phone) were the primary mode of sharing critical ED information. While they lacked in cinematography and polish, their timeliness was much appreciated by faculty, and they were largely successful, allowing panicked questions to be answered with an emailed link. These new "just-in-time" resources were posted on the CTFD and IDTRC websites and publicized through the Faculty Senate email listserv.

Over the course of the spring 2020 semester it had become increasingly clear at CCSU as well as myriad other institutions that issues of student mental health were exacerbated under the stress of the campus closure and the new online reality (Johnson, 2020). But in addition, as noted above, obvious signs of the deleterious effects of stress on faculty and staff had become impossible to ignore. In response to the needs of our faculty and students, our fall kick-off ED event, Still Connected: Supporting Our Students and One Another, was co-hosted with the Center for Social and Emotional Learning. The seminar featured guests from the Center for Counseling and Wellness and other experts in dealing with personal trauma and included important practical information on self-care for faculty as well as concrete suggestions on how faculty could integrate stress management activities into their courses. It was with a sense of hope and a collective held breath that we approached the first day of the fall semester. 


\section{"Houston, We Have a Problem": The Fall Semester Arrives}

Despite the greatly condensed ED timeline for HyFlex (as well as the relatively late availability of BBC and GoReact), the ED team had pulled out all available stops in a unified effort to provide faculty with the necessary tools to have a successful fall semester. But as this section explores, the best-laid plans can be threatened with derailment in a moment's notice.

While nearly 500 course sections had originally been scheduled for HyFlex delivery (out of a total HyFlex classroom capacity for 800 sections), by the second week of the semester, less than 200 (approximately $15 \%$ of the total university sections) remained in that format. Students had not enrolled for on-ground seats in the numbers anticipated (based on predictions from surveys and focus groups). Whether due to concerns over safety, confusion over the registration process required to opt in to the limited number of on-ground seats, or other constraints such as family obligations and/or jobs, many HyFlex sections ended up with fewer than two students registered for in-person seats. Affected faculty were given the option to convert their courses to online only, and they largely voted with their feet, retreating to what was now their pedagogical comfort zone of online synchronous delivery.

This huge shift in modality right after an intensive burst of ED and at a critical time in the semester was just one reason for an increasing sense of burnout among the ED team. While most faculty were openly appreciative of the ED team's work, some failed to understand the necessity of flexibility. For example, a critical mass of faculty did not complete preparation of their BBL course shells sufficiently far in advance of the start of the semester and found that the ED team did not have sufficient time to address their individual needs. As previously explained, in the past many faculty had taken a minimalist approach when using BBL and were therefore caught unaware of the time commitment for crafting a fully operational course shell for an online or HyFlex course.

The live broadcast service provider contracted for the HyFlex classrooms experienced numerous outages during the first two weeks as a result of the increasing demand from schools across the country. 
Faculty had been so focused on Plan A that few had identified a Plan $B$, leading some to cancel affected class meetings. Some had not participated in the HyFlex ED and found themselves unable to navigate the new technology. Live broadcasts were accidentally cut off and recordings unwittingly hidden in the bowels of classroom computers. Simultaneously, students had difficulties navigating the new technology; many did not know where to locate their course's live broadcasts, while others had browser settings that prevented streaming.

This created the perfect storm, with outdated structures exacerbating the situation. Embarrassingly, ED was as siloed as the rest of campus, if not more so. Having originally been part of the Information Technology Department (IT), the IDTRC retained historical legacies that perpetuated confusion and fostered frustration for faculty. Pre-pandemic there were rather sharp lines between the IDTRC, the CTFD, and IT (Table 1). IT, for example, "owned" classroom technology and software, but BBL and instructional software was the "territory" of the IDTRC. IT offered training in Microsoft Teams, the IDTRC trained faculty on BBC and teaching with technology, while both offered training on WebEx. Most importantly, there was a single point of problemsolving contact, as IT and the IDTRC shared a common Help Desk. The HyFlex classes clearly straddled both sides of the house. Faculty and students flooded the Help Desk with calls concerning hardware and livestreams (IT concerns) and questions about how to use the classroom camera settings and BBC chat room (IDTRC training). Calls for help were frequently (albeit inadvertently) shuttled to the wrong side of the house, delaying resolution and increasing aggravation.

The ED team's exhaustion after the compressed HyFlex training timeline and efforts to keep up with Help Desk requests was compounded by public complaints by a small number of vociferous individuals. A game of ED "whack-a-mole" sprang up, whereby faculty would voice a question or frustration to the IDTRC email address or campus-wide listserv about a particular educational technology and a "how-to" video response would appear within a few hours (examples available at https://www.ccsu.edu/ctfd/resources/hyflex.html). 
Table 1. Ownership of Teaching Tools

\begin{tabular}{lll}
\hline Categories & \multicolumn{1}{c}{ Tool } & Responsible party \\
\hline Attendance & Bb tool, Collaborate, participant lists & IDTRC \\
Calendar & Outlook & IT \\
Scheduling & Bookings & IT \\
Communication: & WebEx, MS Teams & IT and IDTRC \\
- Synchronous & Bb Collaborate & IDTRC \\
& Kaltura Classroom & IT and IDTRC \\
- Asynchronous & Outlook email & IT \\
& MS Teams chat/posts & IT \\
LMS & Blackboard & IDTRC \\
General survey & Select Survey & IDTRC \\
& MS Forms & IT \\
Lecture capture & Kaltura Classroom & IDTRC and IT \\
Student opinion surveys & Kaltura Personal Capture & CoursEval \\
\hline
\end{tabular}

Despite the stress and challenges, the result was a significant positive change in faculty comfort with HyFlex over the first month of the semester, as measured by a faculty survey (Figure 1) that was made available to all faculty teaching a HyFlex course at the beginning of fall 2020 and again in mid-September. The initial feedback allowed us to identify areas where additional support would have the greatest benefit and focus our collective energy there. The additional outreach as well as the learning by doing that was happening with each class taught resulted in a marked improvement in comfort and confidence by the time the survey was administered the second time.

Faculty interviewed at the time by the student newspaper also voiced reasonable satisfaction with the experience, noting the opportunity for face-to-face interactions in the classroom was preferable (from a faculty perspective) to a completely online experience, despite the perceived rushed rollout of the technology. One faculty member quoted in the article was already suggesting an expansion in HyFlex offerings for the spring, based on his experience to that point (Brooks, 2020). This enthusiasm was harnessed through a Microsoft Team nicknamed the HyFlexers, created for faculty interested in sharing experiences and asking questions about the technology, and the AVPsupported HyFlex Teaching Exchange (HyTE), a group of HyFlex faculty 


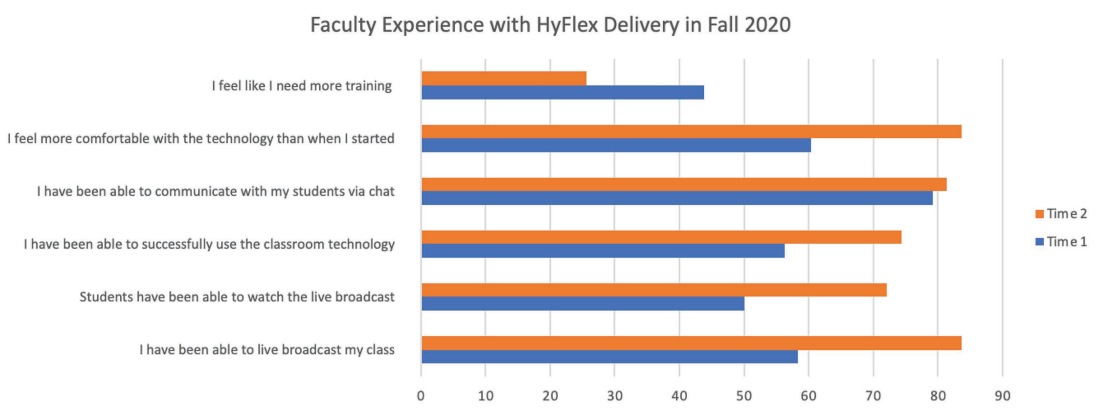

Figure 1. Self-Reported Faculty Experience with HyFlex Delivery

Time 1: 9/1/2020-9/4/2020, based on a sample of 48 full- and part-time faculty

Time 2: 9/10/2020-9/18/2020, based on a sample of 43 full- and part-time faculty

who met virtually on a weekly basis to exchange ideas. HyTE resulted in a number of tangible benefits for the university, including a facultyrun ED workshop describing the "Top Ten" HyFlex teaching tips and a "welcome aboard" video for colleagues teaching HyFlex for the first time in spring 2021.

By the third week of the semester, the deluge of panicked requests for help from faculty had calmed to a manageable trickle, allowing the ED team to catch their collective breath enough to begin addressing the needs of the faculty as a whole. Faculty concerns about cheating (originally expressed in March and addressed in one of the early ED "survival guides") rose to the top of programming requests, a phenomenon seen at many other institutions during the COVID-19 pandemic (Amzalag et al., 2021). The available browser lockdown program was problematic for students to use, and laptop cameras were not universally available. Our students also reported that the online proctoring software significantly added to their text anxiety (Bravo, 2021). The situation became increasingly toxic, with students complaining about both a lack of faculty trust as well as unfair situations in which their classmates were known to be academically dishonest. The result, here and elsewhere, was enhanced student and faculty anxiety (Eaton \& Turner, 2020). A special ED webinar "Academic Honesty in the Age of COVID" 
featured presentations by the Director of the Office of Student Rights and Responsibilities, members of the Academic Integrity Committee, a faculty member who had discovered the illicit use of Chegg in her classroom, and an instructional design professional. Alternatives to online proctoring and pedagogical shifts that minimized opportunities for cheating were highlighted. As with other programming, the interdisciplinary nature of this virtual panel facilitated the ability of faculty in attendance to get their questions answered.

Shortly afterward, a special $\mathrm{CwC}$ event focused on helping faculty create that needed Plan B for their HyFlex and online synchronous classes. Other fall ED focused on encouraging faculty to increase their use of available tools in ways that promoted experimentation and avoided overload. The need to "moderate" ED webinars dissipated, as faculty self-selected the tools they were interested in exploring and settled into a more relaxed relationship with the available technologies.

As the semester progressed and registration for spring 2021 appeared on the horizon, the fate of the university's substantial investment in HyFlex classrooms loomed large. As Skibba (2007, p. 3) noted of hybrid classes in general, HyFlex faculty at CCSU were concerned about "losing personal connection with students," especially with a relatively small number attending physically and the majority attending remotely and/or asynchronously. A September student survey suggested that numerous HyFlex faculty were struggling to successfully engage their remote students; in response, additional ED programming focused on engaging students across modalities. The engagement disparities may have been driven by faculty intuitively focusing on the students in front of them after having spent half a semester teaching strictly online, difficulty dealing with the 30-second delay in the livestream, and/or struggling to juggle the $\mathrm{BBC}$ chat to communicate with students watching synchronously online.

In addition, the 30-second delay had been a "deal-breaker" for faculty in discussion-heavy courses when they had been approached in the summer about teaching HyFlex. In response, the ED team and IT worked collaboratively, providing faculty with the means 
and written training materials to switch from the standard livestream to any of the three supported web conferencing platforms (WebEx, Microsoft Teams, and BBC) in the HyFlex classroom, thereby avoiding the 30-second delay. While only a limited number of faculty switched "mid-stream" during the semester from one HyFlex broadcast platform to another, the ability to avoid the dreaded 30-second delay (and with it the multitasking associated with using $\mathrm{BBC}$ chat to communicate with students attending remotely) effectively opened the HyFlex pedagogy to a significant number of future courses.

Preparation for spring 2021 therefore integrated the lessons learned in the fall 2020 HyFlex rollout with the addition of new platforms, necessitating the availability of additional training opportunities (all under the looming threat of another possible campus closure if pandemic conditions warranted). With this in mind, the team constructed a detailed ED calendar, laying out a schedule of on-ground workshops for faculty stretching from November through mid-January rather than an intensive burst in January. The change was designed to both better manage ED team stresses as well as deal with any potential short-term closure of campus (and with it, the inability to deliver in-person training). While no closure manifested, faculty still fell into old habits of procrastination; timely reminders of the availability of workshops were therefore required, and, in the end, additional January ED sessions were scheduled.

While some faculty embraced the new opportunities to utilize web conferencing platforms in the HyFlex classroom, others preferred to stay with the original livestream program, at least partially due to the automatic scheduling of broadcasts and recordings and the automatic uploads of the latter. To facilitate faculty decisions as to which modality best suited their pedagogical needs, a detailed grid comparing the original livestream program, Microsoft Teams, WebEx, and BBC was developed, and faculty could select between ED focusing on the original livestream or web conferencing platforms. Members of the ED team self-selected whether to lead the livestream technology or web conferencing workshops or mentor special guided practice sessions 
in a HyFlex classroom, thereby ensuring consistency in the ED. Faculty were also given the opportunity to view selected workshops remotely, experiencing a "student-view" of the different technologies.

In the end, while there was only a $10 \%$ increase in the number of faculty members teaching HyFlex in the spring 2021 versus fall 2020 semesters (193 vs. 175), there was a $75 \%$ increase in the number of HyFlex sections (340 vs. 194). Faculty who had taught a single HyFlex course in the fall elected to teach multiple courses in this modality in the spring semester, with some faculty teaching their entire load as HyFlex. The number of on-ground students per HyFlex section was also notably higher in spring 2021 ( 8.30 vs. 5.86).

Other ED resources specifically targeting known difficulties and stressors were made available to faculty in the run-up to spring 2021. These include a special HyFlex template for BBL course shells, a HyFlex checklist for faculty (including a suggested timeline for selected events, such as notifying students as to how they will access synchronous class meetings online), and suggested syllabus language concerning the availability of a Plan B for synchronous class meetings in the event that the preferred modality is temporarily unavailable.

Two large January events directly addressed areas of ongoing concern. An online survey targeting the specific needs of part-time faculty revealed a desire for more training in BBC, which became (along with self-care) the focus of a special evening virtual ED event for these colleagues. The traditional spring kickoff workshop, titled "Communicating Effectively in Physical and Virtual Space," brought together a panel of faculty, staff, and administrators to share stories of communication with students and the learning opportunities they presented. A second panel of faculty experts explored how to effectively communicate with students from other cultures and those who are experiencing trauma and loss and respect students' intersectional identities. These three themes also provided the foundational topics for follow-up Lunch and Learn workshops offered over the spring 2021 semester. The teething pains of the fall drove a renewed sense of cutting-edge ED and with it the promise of greatly improved online/HyFlex modality in the spring. 


\section{Closing the Loop: Lessons Learned and Preparing for the "After Time"}

Despite the initial hiccups, the HyFlex classrooms offer great promise, including the potential of an expanded suite of online graduate degrees and the ability to effectively serve geographically dispersed students enrolled at other institutions. Student teachers and seasoned faculty members alike can utilize the technology to be self-reflective about their own teaching while the university has the opportunity to host hybrid professional conferences. Likewise, while the introduction of so many new technological tools and software packages over a short time placed a great deal of stress upon the ED team, faculty have been able to expand their suite of pedagogical tools and engage their students in fresh ways. After spending the time and effort to master these new tools, faculty will certainly be reticent to abandon those they find successful and will instead look for ways to adapt them to the traditional on-ground classroom. While the pandemic will eventually come to an end, in many ways teaching and learning has been changed forever.

In reflecting on the ED team of CCSU's experiences of the past 15 months, the following lessons float to the top of our collective consciousness:

\section{Pedagogical Technologies Are Only as Useful as Their Rollout}

As in the old adage against simply throwing money at a problem in hopes of a solution, throwing technology at a problem often yields dubious results. In order for new technologies to reach their maximum effectiveness, sufficient time needs to be allotted for the rollout. Specifically, ED staff need sufficient time to master the technology themselves and create and troubleshoot training materials. In turn, faculty need sufficient time and opportunities to absorb, practice, integrate, and develop comfort in said technology. Although a faculty member lauded the quality of the HyFlex training in an article in the student newspaper, she simultaneously noted that "the window for training 
was short" and the "opportunity for faculty in August to familiarize themselves with the equipment was limited" (Brooks, 2020). Successful ED is holistic, integrating training in hardware, software, and pedagogy. It is not sufficient to know the tool exists, or even how to use it; one must also recognize under which circumstances it is best to use that tool. In addition, the number of potential difficulties introduced by educational technology tracks the number of choices a faculty member is given. Academic freedom creates a double-edged sword for ED staff.

\section{Success in the Workshop Mirrors Success in the Classroom}

Not surprisingly, practices that enhance student learning in the classroom can be utilized to enhance the efficacy of ED workshops, including online ED (Buckley, 2020). These include offering information in multiple modalities (e.g., written instructions, videos, and live workshops); chunking large modules of online learning into shorter components (Méndez-Carbajo \& Wolla, 2019); recording live workshops for later reference; offering small-group experiences, hands-on workshops, and practice sessions when practical; having additional help in moderating questions in large webinars (similar to teaching assistants in large lecture sections); and always operating in the spirit of flexibility-know when to embrace the less elegant but more timely seatof-your-pants approach in favor of waiting to produce a polished, "professional" product.

\section{Effective ED Involves Both Faculty Development and Student Development}

Responses on student surveys and in focus groups, as well as anecdotal evidence, revealed that many students felt they had not been instructed on how to find their live broadcasts and chats (or even online courses in general) and were floundering when it came to troubleshooting software. These difficulties were exacerbated by closure 
of on-ground computer labs where students could access technology with IT staff there to help them. While in the short-term hastily created low-tech YouTube videos filled the gap, these issues must be addressed as a central part of effective course design. Faculty and ED professionals need to be proactive in reaching out to students before the start of the semester to help them navigate unfamiliar software and platforms. For example, the rollout of Ultra base navigation in Blackboard on our campus was accompanied by the production of separate instruction videos for faculty and students.

\section{Faculty and Student Voices Are Central to Successful ED}

In the early months of the campus closure, faculty leaders in ED organically self-identified and became a valuable part of the ED team. Not only did they provide leads on potential topics for ED workshops, but in many cases they led these events and acted as peer-mentors for their colleagues. Students are also an excellent source of inspiration for timely ED topics. Keep your ear out for campus-wide student surveys or focus groups and ask that ED staff be included in the reporting loop when data on student concerns are collected. In addition, the front page of the campus newspaper (or its website) will often highlight pedagogical issues on campus. ED opportunities are more likely to make a positive impact on student learning and success if they are based on timely evidence of the needs of your particular campus (Ankeny et al., 2018).

\section{Think Holistically}

Faculty (and ED staff) are human beings first, and as we experienced firsthand during the pandemic, are susceptible to anxieties akin to those of students. Just as stress can prevent students from learning effectively, work-life issues can gravely impact the ability of faculty to reap the benefits from even the most carefully crafted ED. As a result, ED staff should work in collaboration with relevant offices 
across campus (in our example, the Center for Social and Emotional Learning, Center for Counseling and Wellness, Office of Equity and Inclusion, and Office of Student Rights and Responsibilities). Be on the lookout for signs of burnout, among both the faculty and ED staff.

\section{Silos Are for Corn, Not ED}

The greatest benefit of the pandemic was the spirit of seamless teamwork that developed between the CTFD and IDTRC, demonstrating that the most successful ED teams include faculty, pedagogical software specialists, administrators, and course development experts. The silo/bunker mentality doesn't work in an environment that values flexibility and the ability to adapt to changing conditions. As the dust began to settle and we caught our collective breath, our blended ED family began modeling the change we wanted to see across our institution. It is a credit to our hard-won successes in helping faculty improve their pandemic pedagogy that the administration accepted our proposal for a formal merger of our centers into the Center for Teaching and Innovation (CTI) so we could operate as a fully integrated one-stop shop for faculty ED needs. Based on our shared experiences, both centers willingly relinquished a fraction of their individual identity to gain so much more. Something that would have been painful prior to March 2020 became almost effortless.

The overarching lesson of our campus's pandemic response to teaching and learning was that relationships, rather than individuals, form the heart of successful CTLs and hence, by extension, successful ED (Little, 2014). While admittedly rushed in the beginning, the ED practices and structures revised and developed at CCSU in response to the COVID-19 pandemic have benefited our students and faculty in the long run in ways that will extend far beyond the reach of the pandemic. As we have honestly presented here, there were significant disappointments and challenges faced along the way, but these, too, ultimately led to an overall improvement in ED at our institution. Above all else, we have learned that the university functions best when we 
are all listening and learning together. It is through the destruction of silos and through an organic, respectful, and meaningful sense of teamwork that focuses on the needs of faculty and students that we hope to reach our potential as an institution of higher learning, in preparation for an "after time" rather than merely a return to the "before time."

\section{Biographies}

Kristine Larsen, Ph.D., is Professor of Astronomy in the Geological Sciences Department at Central Connecticut State University and Coordinator of Faculty Development and Teaching Innovation. Her research and teaching focus on the intersections between science and society, including the misuses of science by popular culture. Her books include Particle Panic! (2019), The Women Who Popularized Geology in the 19th Century (2017), and The Mythological Dimensions of Doctor Who (2010).

Christina Robinson, Ph.D., is Associate Vice President for Graduate Studies, Research, and Faculty Development at Central Connecticut State University. Her research and professional activity focus on systematic reductions in economic and social inequality. In her role as the executive director for educational development she strives to creating an engaging and responsible campus culture and views educational development as a catalyst for change and growth.

Jason A. Melnyk, Ph.D., is Professor of Exercise Science at Central Connecticut State University as well as Associate to the Center for Teaching and Innovation. He is a past-President and chair of the Technology committee for the New England American College of Sports Medicine.

Jennifer Nicoletti is Director of Instructional Design and Distance Learning Development at Central Connecticut State University. She 
has over twenty years' experience focused on instructional technology for higher education and LMS Systems Administration, many of those spent supporting faculty with content development initiatives, creating programs to leverage digital platforms and developing strategies for online course quality.

Amy Gagnon received her MA from Central Connecticut State University in public history and has taught graduate level history courses at CCSU. Her published work appears in both scholarly journals and mainstream magazines. She serves as Operations Assistant for the Center for Teaching and Innovation, helping faculty navigate programming and resources at the university.

Kelly McLaughlin received her MS in Educational Technology from CCSU. She was an Instructional Coordinator and Blackboard Administrator at CCSU from 2017-2021. Prior to making the switch to higher education, Kelly was a 4th grade teacher for seven years.

Mina Hussaini holds an MS in Technology Management from CCSU. She joined the ED team at CCSU during the pandemic, as an Instructional Design and Distance Learning Development Assistant. Teaching and helping faculty with technologies is very rewarding to her because she enjoys seeing them conquer their fears and feeling empowered to learn more.

\section{References}

Ankeny, C. J., Mayled, L. H., Ross, L., Hjelmstad, K. D., Krause, S. J., Middleton, J. A., \& Culbertson, R. J. (2018). Creating and scaling an evidencebased faculty development program [Paper presentation]. 2018 ASEE Annual Conference \& Exposition, Salt Lake City, UT, United States. https:// www.asee.org/public/conferences/106/papers/23176/view

Beatty, B. J. (2019). Hybrid-flexible course design. EdTech Books. https:// edtechbooks.org/hyflex 
Bravo, J. (2021, May 3). Should Proctorio be used by colleges? The Recorder. https://centralrecorder.org/77254/news/should-proctorio-be-usedby-colleges/

Brooks, R. (2020, September 27). CCSU faculty weigh in on HyFlex model. The Recorder. https://centralrecorder.org/75210/news/ccsu-faculty-weigh-in-onhyflex-model/

Buckley, H. (2020). Faculty development in the COVID-19 pandemic: So close-yet so far. Medical Education, 54(12), 1189-1190. https://doi.org $/ 10.1111 /$ medu. 14250

Chan, I. (2020, May 8). Students wonder what lies ahead for next semester. The Recorder. https://centralrecorder.org/74147/news/students-wonderwhat-lies-ahead-for-next-semester/

Cordaro, M. (2020). Pouring from an empty cup: The case for compassion fatigue in higher education. Building Healthy Academic Communities Journal, 4(2), 17-28. https://doi.org/10.18061/bhac.v4i2.7618

Duffield, S., \& O'Hare, D. (2020). Teacher resilience during coronavirus school closures. The British Psychological Society. https://www.bps.org.uk/sites/ www.bps.org.uk/files/Member\%20Networks/Divisions/DECP/Teacher\%20 resilience\%20during\%20coronavirus\%20school\%20closures.pdf

Eaton, S. E., \& Turner, K. L. (2020). Exploring academic integrity and mental health during COVID-19: Rapid review. Journal of Contemporary Education Theory \& Research, 4(1), 35-41. https://files.eric.ed.gov/fulltext/ED608658.pdf

Hogan, R. L., \& McKnight, M. A. (2007). Exploring burnout among university online instructors: An initial investigation. The Internet and Higher Education, 10(2), 117-124. https://doi.org/10.1016/j.iheduc.2007.03.001

Jennings, C., \& Wargnier, J. (2011). Effective learning with 70:20:10: The new frontier for the extended enterprise. CrossKnowledge. https://alberon partners.com/wp-content/uploads/2019/09/Alberon_Wargnier_201170-20-10_vEN.pdf

Johnson, R. (2020, April 20). Students stressed out due to coronavirus, new study finds. Best Colleges. https://www.bestcolleges.com/blog/corona virus-survey/

Kelly, A. P., \& Columbus, R. (2020, July). College in the time of coronavirus: Challenges facing American higher education. American Enterprise Institute. https://www.aei.org/wp-content/uploads/2020/07/College-inthe-Time-of-Coronavirus.pdf?x88519

Little, D. (2014). Reflections on the state of the scholarship of educational development. To Improve the Academy, 33(1), 1-13. https://doi.org/ 10.3998/tia.17063888.0033.104

Major, C. (2020). Innovations in teaching and learning during a time of crisis. Innovative Higher Education, 45, 265-266. https://doi.org/10.1007/ s10755-020-09514-w 
Méndez-Carbajo, D., \& Wolla, S. A. (2019). Segmenting educational content: Long-form vs. short-form online learning modules. American Journal of Distance Education, 33(2), 108-119. https://doi.org/10.1080/08923647.20 19.1583514

Miller, A. N., Sellnow, D. D., \& Strawser, M. G. (2021). Pandemic pedagogy challenges and opportunities: Instruction communication in remote, HyFlex, and BlendFlex courses.

Communication Education, 70(2), 202-204. https://doi.org/10.1080/0363452 3.2020.1857418

Nguyen, T. (2020, May 17). Faculty open up about mental health under the COVID-19 pandemic. Chemical \& Engineering News. https://cen.acs.org/ careers/diversity/Faculty-open-mental-health-under/98/i19

Skibba, K. (2007). How faculty roles transform in Hybrid courses [Paper presentation]. 23rd Annual Conference on Distance Teaching and Learning, Madison, WI, United States. https://courses.dcs.wisc.edu/design-teaching/ FacilitationManagement_Spring2016/facilitation-module/1_Online_ Instructor_Roles/resources/skibba_hybrid-roles.pdf

Smith, B. L., MacGregor, J., Matthews, R. S., \& Gabelnick, F. (2004). Learning communities: Reforming undergraduate education. Jossey-Bass. 


\section{Appendix: Glossary of Acronyms}

AVP: Associate Vice President for Graduate Studies, Research, and Faculty Development

BBC: Blackboard Collaborate

BBL: Blackboard Learn

CTFD: Center for Teaching and Faculty Development

CwC: Connecting with Colleagues series

HyTE: HyFlex Teaching Exchange

IDTRC: Instructional Design and Technological Resource Center

IT: Information Technology Department

SA: $\quad$ Special Assistant to the AVP

UDL: $\quad$ universal design for learning 